\title{
Obesity prevention and the primary care pediatrician's office
}

\author{
Eliana M. Perrin ${ }^{\mathrm{a}}$, Joanne P. Finkle ${ }^{\mathrm{b}}$, and John T. Benjamin ${ }^{\mathrm{a}}$ \\ aDepartment of Pediatrics, University of North Carolina at Chapel Hill School of Medicine, Chapel Hill, \\ North Carolina, USA \\ bDepartment of Nutrition, University of North Carolina at Chapel Hill School of Public Health, Chapel Hill, \\ North Carolina, USA
}

\begin{abstract}
Purpose of review-The obesity epidemic confronts the pediatrician every day in the office. Pediatricians should help curb the epidemic through prevention and the usual pediatric primary care tasks of screening, communication and anticipatory counseling. This review highlights findings from recent literature to guide office-based prevention of obesity in children.
\end{abstract}

Recent findings-More and more, children and society feel the effects of the obesity epidemic; prevention efforts need to begin earlier. Pediatricians' efforts to screen help identify at-risk children who may benefit from early lifestyle changes. The identification of overweight children also helps foster the appropriate work up of comorbidities. Pediatricians' communication of weight trajectories, which includes techniques like motivational interviewing, may help parents to adopt behavioral prescriptions. Pediatricians should focus on promoting breastfeeding, limiting television, increasing physical activity and reducing sugar-sweetened beverages. New tools used in the training setting show promising results.

Summary-Pediatricians must focus efforts on preventing childhood overweight, while awaiting effective treatment options for this chronic illness with its many associated morbidities. Such prevention involves sensitively communicating early body mass index screening results to parents and helping them to adopt key behavioral changes in diet and physical activity.

\section{Keywords}

body mass index; children; communication; obesity; physical activity; screening

\section{Introduction}

Recent research reveals that $17 \%$ of US children are overweight, and prevalence has risen in the last several years $[1 \bullet \bullet]$. Despite the rising normative societal weight, negative weight stereotypes persist [2•] and increasing weight is associated with emotional distress [3•] in addition to previously known medical complications. Pediatric overweight can predict adult overweight [4], with its own health consequences including coronary artery disease. Unfortunately, few treatment interventions addressing pediatric overweight have been successful [5॰], and those that are successful are time and resource-intensive [6]. We logically conclude that to make headway in overcoming this epidemic, pediatricians must focus efforts on preventing obesity and start early in childhood to do so. The review will focus on the early 
institution of obesity prevention messages, methods of screening for unhealthy weight trajectories that can be used in the pediatrician's office, the importance of sensitively communicating the results of that screening to parents and their families, and techniques for counseling.

\section{The importance of early obesity prevention}

In order to put the obesity epidemic in perspective and to highlight why early prevention is of utmost importance to the primary care pediatrician, it is helpful to review some statistics. While over $17 \%$ of American children aged 2-19 are overweight [1 $\bullet \bullet]$, these prevalence rates are even higher for certain subpopulations such as Hispanic and African-American children $[1 \bullet \bullet, 7 \bullet$, 8•]. Resource utilization and expenditures analysis reveal overweight children escalate costs for healthcare [9].

The need for prevention programs at the earliest point possible in a child's life is best supported by weight trends seen in young children. From 1989 to 2000, 17 new states reported a prevalence of over 10\% of overweight in 2, 3 and 4-year-olds [10], and the prevalence of overweight in a nationally representative sample of 3-year-olds from urban, low-income families was $35 \%$ [7•].

In a cohort of inner-city Philadelphia children, overweight began very young and persisted, which dramatizes the importance of early intervention [11••]. Other reasons for the pediatrician to focus efforts on the early years relate to the fact that younger children visit their pediatricians more frequently than older ones. Parents also have more control over feeding and activity patterns in early childhood, and, therefore, play a role in young children's formation of important food and activity habits $[12 \bullet, 13]$. Pediatricians can begin their obesity prevention counseling before or at the time of a baby's birth by promoting breastfeeding. Recent inquiry confirms earlier reports that breastfeeding reduces later risk for obesity [14•]. The Centers for Disease Control and Prevention [15] recently reported that disparities in breastfeeding rates between non-Hispanic white children and non-Hispanic black children persist in most socioeconomic subgroups. We believe these disparities may contribute to later disparities in overweight prevalence, making it especially important for pediatric and public health efforts to target these populations with messages promoting breastfeeding. As infants start transitioning to solid foods, and start crawling and walking, pediatricians play an important role in monitoring growth, counseling parents on healthy eating habits [16•], and stressing with parents the important role they play in raising active children. New research shows that even short-in-duration lifestyle changes can have impact on atherosclerotic factors [17•].

Another reason for physicians to focus their efforts early in childhood is that body mass index $\left(\mathrm{BMI}=\mathrm{kg} / \mathrm{m}^{2}\right)$ at young ages tracks well into older ages [18••]. In one study, while two in five children whose BMIs were $50 \%$ or greater by age 3 years were overweight at age 12 , none of the children whose BMIs were below 50\% were overweight at age 12 [18••]. BMI is particularly useful for screening purposes during the time of adiposity rebound - a physiologic phenomenon when the BMI begins to increase again after reaching its nadir (typically around age 5-6) [19]. Problematic adiposity rebound is that which occurs as early as 3 years of life and is associated with an increase in metabolic diseases such as diabetes [20••]. Pediatricians who observe a child's BMI starting to trend upward during the early preschool period should be particularly concerned.

\section{Barriers to prevention}

Pediatricians are well positioned to lead efforts to prevent unhealthy weight patterns in children, yet many feel ineffective in their efforts to combat this epidemic. Pediatricians cite several barriers to overweight prevention counseling, including a lack of time, a perceived 
ineffectiveness and the parent's lack of motivation [21]. Low parental motivation may come from unawareness, with recent research confirming previous conclusions that parents of overweight children often do not recognize their children as overweight and may even fail to recognize the health risks of increased weight $[22 \bullet, 23 \bullet]$. Lack of recognition and lack of concern about overweight do seem correlated $[23 \bullet, 24]$. Pediatricians also report their own low self-efficacy as a barrier in managing overweight $[25 \bullet, 26]$. In contrast, physicians who were aware of obesity recommendations were more likely to report their counseling as efficacious [21]. Recent analysis of surveys of the Pediatric Research in Office Settings network of nearly 2000 providers found that strategies to prevent and treat obesity would be a top-line requested inquiry [27•].

Providers can also lack accurate visual assessment and, as a result, underdiagnose overweight in children [28 $]$. Young children are particularly underdiagnosed with only $31 \%$ of overweight preschoolers versus $76 \%$ of overweight adolescents so identified [29]. Pediatric providers only infrequently use recommended Centers for Disease Control and Prevention age and genderspecific BMI charts [30], explicitly designed to help screen for unhealthy weight trajectories. The American Academy of Pediatrics has recently reaffirmed its stance that BMI should be used regularly to screen children for risk for overweight [31••].

\section{Role of the pediatrician in early prevention}

In spite of these barriers, growing evidence, acknowledged in national policy statements, suggests that pediatricians should incorporate into their regular practice counseling about healthy weight management. Specifically, pediatricians should, at a minimum, recommend parents enact healthy weight behavioral changes which carry no or minimal harm $[31 \bullet \bullet, 32]$. These no-risk recommendations may include limiting television, limiting sweetened drinks, and increasing physical activity, especially in children more likely to be overweight.

Finding time to add even the minimum prevention efforts into a busy practice can be a challenge. Researchers and practitioners are working to find the right methods of screening that will address barriers and facilitate early prevention efforts. Some studies reveal that newly developed curricula may help in training physicians $[33,34]$ whose program directors face curricular barriers [35•].

\section{Methods of screening}

At the University of North Carolina at Chapel Hill, the Department of Pediatrics and the Center for Health Promotion and Disease Prevention have developed age-specific practical officebased tools to help physicians communicate BMI results, and assess the patient's and family's readiness to change in both dietary and physical activity habits. Specific assessment questionnaires, which provide the healthcare provider with explicit advice, are now being studied, but are not yet available for distribution. At the University of North Carolina at Chapel Hill, BMI screening starts as recommended at age 2 years, but other age-specific tools are begun in infancy. These tools have proven effective in our clinics to help parents change unhealthy behaviors, and to boost pediatric resident confidence in nutrition and physical activity anticipatory guidance $[33,36]$. These tools were based on prior pediatrician survey results and focus group findings $[25 \bullet, 26,30]$. We will discuss screening in some detail and will mention other methods that pediatricians might use to focus on obesity prevention in their offices.

\section{Using body mass index to screen and monitor children}

In 2000, the Centers for Disease Control and Prevention distributed BMI charts and designated children 'at risk of overweight' as those with $\mathrm{BMI} \geq 85$ th percentile and 'overweight' children 
as those with BMI $\geq 95$ th percentile [37]. BMI is a reasonable reflection of body fat and is correlated with health consequences [4,38].

The American Academy of Pediatrics Committee on Nutrition recently reaffirmed [31••] its 2003 recommendation [39] that pediatricians perform regular BMI screening in children.

Identifying overweight is associated with a greater rate of comorbidity screening [40••]. This recommendation echoes that of the Institute of Medicine, which provided its recommendations 'based on the best available evidence - as opposed to waiting for the best possible evidence' [41].

BMI, as opposed to height and weight charting of the same hypothetical overweight child, was more likely to flag overweight status to pediatricians and prompt greater concern [30].

Pediatricians should use height, weight, and resultant BMI calculation and plotting on age and gender-adjusted Centers for Disease Control and Prevention BMI charts to classify children as 'healthy weight', 'at risk' or 'overweight' for all children above 2 years of age. See Table 1 to determine appropriate BMI weight status category after measuring, calculating and plotting on the appropriate gender chart by age.

While there are numerous barriers to using BMI to identify overweight children, practice level changes and the incorporation of BMI into office systems and electronic medical records can facilitate regular use [25•]. Although the evidence is early, we suggest plotting BMI on colorcoded charts [33,42]. This technique flags a child's risk for both the pediatrician and parent in a clear stop-light-coding assigned to healthy weight (green), at risk (yellow) and overweight (red) like the familiar asthma action plan.

In addition to focusing on BMI, pediatricians also need to assess parental readiness to make change. Some parents are not interested in change, but others can become motivated to change after hearing the pediatrician's perception of the child's weight and the resultant health risks of that weight [43]. We hypothesize that sensitive communication of BMI results to parents who are often unaware of their child's weight status may be a motivator to change dietary and physical activity behaviors.

\section{Nutritional and physical activity issues to focus on in the pediatric office}

The evidence-base for the effectiveness of behavior modification in preventing obesity in children lacks high numbers of randomized, controlled trials. There is, however, still evidence to support behavioral recommendations to parents. The three behaviors that we believe are of most importance to the practicing pediatrician are limiting 'screen' time, limiting sugarsweetened beverages and increasing physical activity.

Recent research echoes prior findings that television-watching time and risk for overweight are highly associated [44•]. In one recent study, girls who watched $2 \mathrm{~h}$ or more of television per day at ages 7, 9 and 11 were over 13 times as likely to be overweight at age 11 [45•]. Children with a television in their bedroom are at higher risk for childhood overweight [46•]. Parents are often unaware of the relationship between young children's screen time and their risk for overweight [47]. Given this lack of awareness and one important randomized trial showing that reduction in total number of hours of television and videocassettes was associated with a relative reduction in BMI [48], we believe it high yield for pediatricians to counsel in this realm.

A recent environmental intervention to decrease sugar-sweetened beverages was effective and resulted in a beneficial body weight trend that was more extreme for those of higher baseline body weight [49•]. Recent analysis of the National Health and Nutrition Examination Survey 1999-2002, however, found that preschool children's beverage consumption was associated 
with an increase in total energy intake, but not with their BMI [50]. We and the authors agree that follow-up of these young children through the years of adiposity rebound may be necessary. Given prior evidence of the relationship between sweetened drinks and adiposity, we recommend that pediatricians advise parents to limit these highly calorie-dense beverages.

Physical activity is considered the key to preventing overweight and yet $55 \%$ of adolescents in some samples fail to meet physical activity guidelines [51•]. In young children, physical activity is related to overweight. A review of six clinic-based populations who were overweight or at risk who received interventions to decrease sedentary behavior resulted in behavior change and improved weight indices [52•]. We refer the readers to an earlier thorough review of this topic [53•].

\section{Assessment of family, dietary and physical activity behaviors}

A parent can complete in the waiting room a survey, like the age-specific practical office-based tool being developed at the University of North Carolina at Chapel Hill, that assesses parental readiness to change, and family nutrition and physical activity habits. The physician can then use the results as a way to begin conversation with a family about the outcome of BMI screening and important obesity prevention measures, such as limiting 'screen' time, limiting sugarsweetened beverages and increasing physical activity.

Ways to change unhealthy habits and counseling points for the physician on each topic can also be included. As with BMI, all results from the parent survey must be sensitively communicated to parents. Table 2 gives examples of nutrition, physical activity and readiness to change questions and examples of tips from the current screening questionnaire, being studied at the University of North Carolina at Chapel Hill.

\section{Communication of screening results to children and their families}

Informing children and parents that the child is at risk for overweight or actually overweight is critically important, but often not welcomed by either parent or child. It can be helpful for the pediatrician to have learned the family's readiness to change. If, after assessing readiness to change, the pediatrician determines the family is not ready for next steps, the pediatrician can plant the seed about the importance of the topic and convey how addressing physical activity and healthy diet might be consistent with the family's goals as well. The subject can then be put aside to address at a different time when the family is more ready. Parents and children should not be put on the defensive about weight. Physicians should sensitively communicate a child's weight status as healthy, at risk for overweight, or overweight, but the focus on the discussion should be on healthy nutrition and healthy activity habits, not weight.

Should the family be interested in making changes, they should be engaged in choosing how to get started. In general, recommendations made by the pediatrician should target the behaviors for which there is the most promising evidence. It must always be kept in mind that some parents may feel guilty about the weight status of their children and/or their dietary or physical activity habits. Indeed, a sensitive approach is always needed when discussing overweight and lifestyle changes with parents. We suggest talking with families to identify just one to two goals per visit so as not to overwhelm the patient. Table 3 offers an example script of a conversation between physician and parent to communicate weight status and introduce goal setting.

Although many studies throughout the world are currently attempting to determine how and why people adopt new healthier behaviors, and how and why parents may do so on behalf of their children, one strategy that appears promising is motivational interviewing. Evidence in the form of randomized clinical trials supports the efficacy of the use of motivational 
interviewing for addictive behaviors, but is not yet well established for prevention or treatment of pediatric obesity [54••]. The hallmarks of motivational interviewing — reflective listening, shared decision making and agenda setting — and the use of 'pull' rather than 'push' techniques tend to foster a patient-centered approach, resulting in higher patient satisfaction and better outcomes in studies cited by a recent review [54・•].

A summary of what we recommend for obesity prevention screening is diagrammed in Fig. 1. This approach could certainly be used at all well child visits and many sick visits. Obesity prevention should not just focus on the at-risk or overweight child, but should also include the child of healthy weight. Pediatricians should view crossing BMI percentiles in the upward direction and the 'at-risk' zone as warning flags and opportunities for targeted prevention counseling. New inquiry reveals that identifying children as at risk or overweight results in greater odds of overweight management [40••]. Even more promising, physician counseling about adolescent overweight was recently associated with attempted weight loss and dietary behaviors according to a recent analysis [55•].

\section{Conclusion}

Pediatricians should devote significant energy to obesity prevention starting in the early years of life. They should screen early for unhealthy weight trajectories using BMI and age and gender-adjusted BMI charting and survey tools; sensitively communicate with parents the results of that screening; review with parents and older patients their answers to questions about dietary and physical activity and readiness to change; and counsel sensitively using motivational interviewing and other patient-centered techniques.

We believe the future control of the obesity epidemic will be in its prevention. Regular attention at each health assessment visit needs to be focused on helping children achieve healthy dietary and physical activity patterns. Practitioners need to prioritize this approach in all their children, whether at risk for overweight, overweight or healthy weight.

\section{Abbreviation}

BMI, body mass index.

\section{References and recommended reading}

Papers of particular interest, published within the annual period of review, have been highlighted as:

- of special interest

• of outstanding interest

1. Ogden CL, Carroll MD, Curtin LR, et al. Prevalence of overweight and obesity in the United States, 1999-2004. JAMA 2006;295:1549-1555.1555 [PubMed: 16595758]This paper is important because it provides a current estimate of the prevalence of overweight in children and adolescents based on an analysis of the 2003-2004 National Health and Nutrition Examination Survey, and shows that, even in the last several years, youth prevalence rates for obesity are still increasing.

2. Greenleaf C, Chambliss H, Rhea DJ, et al. Weight stereotypes and behavioral intentions toward thin and fat peers among White and Hispanic adolescents. J Adolesc Health 2006;39:546-552.552 [PubMed: 16982390]This paper describes the negative stereotypes that persist about overweight children among both White and Hispanic youth. In this study, weight stereotypes were equal in both groups.

3. Young-Hyman D, Tanofsky-Kraff M, Yanovski SZ, et al. Psychological status and weight-related distress in overweight or at-risk-for-overweight children. Obesity (Silver Spring) 2006;14:2249_ 
2258.2258 [PubMed: 17189553]This paper describes the association between emotional distress and weight status in all groups, yet how this relationship differs for boys and girls as well as black and white children.

4. Janssen I, Katzmarzyk PT, Srinivasan SR, et al. Utility of childhood BMI in the prediction of adulthood disease: comparison of national and international references. Obes Res 2005;13:1106-1115. [PubMed: 15976154]

5. McCallum Z, Wake M, Gerner B, et al. Outcome data from the LEAP (Live, Eat and Play) trial: a randomized controlled trial of a primary care intervention for childhood overweight/mild obesity. Int J Obes (Lond). 2006 [Epub ahead of print].This randomized controlled intervention trial reports that four standard general practice consultations over 12 weeks in overweight children aged 5-10 did not result in sustained BMI reduction, suggesting a more intensive approach may be required.

6. Epstein LH, Valoski A, Wing RR, et al. Ten-year outcomes of behavioral family-based treatment for childhood obesity. Health Psychol 1994;13:373-383. [PubMed: 7805631]

7. Kimbro RT, Brooks-Gunn J, McLanahan S. Racial and ethnic differentials in overweight and obesity among 3-year-old children. Am J Public Health 2007;97:298-305.305 [PubMed: 17194857]This study is important because it demonstrates the need for early prevention efforts by providing evidence of overweight in especially Hispanic 3-year-olds from urban, low-income families.

8. Wang Y, Zhang Q. Are American children and adolescents of low socioeconomic status at increased risk of obesity? Changes in the association between overweight and family income between 1971 and 2002. Am J Clin Nutr 2006;84:707-716.716 [PubMed: 17023695]This paper is an interesting examination of the relationship between socioeconomic status and overweight, concluding that reducing income disparities may not be enough.

9. Hampl SE, Carroll CA, Simon SD, et al. Resource utilization and expenditures for overweight and obese children. Arch Pediatr Adolesc Med 2007;161:11-14. [PubMed: 17199061]

10. Sherry B, Mei Z, Scanlon KS, et al. Trends in state-specific prevalence of overweight and underweight in 2- through 4-year-old children from low-income families from 1989 through 2000. Arch Pediatr Adolesc Med 2004;158:1116-1124. [PubMed: 15583095]

11. Robbins JM, Khan KS, Lisi LM, et al. Overweight among young children in the Philadelphia healthcare centers: incidence and prevalence. Arch Pediatr Adolesc Med 2007;161:17-20.20 [PubMed: 17199062]Additional important support for early prevention is provided through this retrospective cohort analysis of overweight in 3 to 7-year-old low-income, inner-city children, which revealed overweight started very young and persisted.

12. Farrow C, Blissett J. Does maternal control during feeding moderate early infant weight gain? Pediatrics 2006;118:e293-e298.e298 [PubMed: 16882774]This study is an interesting examination of maternal control of feeding through observation in 6 to 12-month-old infants and its relationship to child weight status.

13. Wardle J, Carnell S, Cooke L. Parental control over feeding and children's fruit and vegetable intake: how are they related? J Am Diet Assoc 2005;105:227-232. [PubMed: 15668680]

14. Weyermann M, Rothenbacher D, Brenner H. Duration of breastfeeding and risk of overweight in childhood: a prospective birth cohort study from Germany. Int J Obes (Lond) 2006;30:12811287.1287 [PubMed: 16505835]This study provides further evidence for a positive effect on weight status of breastfeeding for a duration of at least 6 months.

15. Centers for Disease Control and Prevention. Racial and socioeconomic disparities in breastfeeding — United States, 2004. MMWR Morb Mortal Wkly Rep 2006;55:335-339. [PubMed: 16572102]

16. Allen RE, Myers AL. Nutrition in toddlers. Am Fam Physician 2006;74:1527-1532.1532 [PubMed: 17111891]A nice summary of the current dietary and behavioral recommendations for feeding toddlers.

17. Roberts CK, Chen AK, Barnard RJ. Effect of a short-term diet and exercise intervention in youth on atherosclerotic risk factors. Atherosclerosis 2007;191:98-106.106 [PubMed: 17054960]Examines the impressive anti-atherosclerotic effects of a high-fiber, low-fat diet in just a 2-week residential program designed for overweight children.

18. Nader PR, O'Brien M, Houts R, et al. Identifying risk for obesity in early childhood. Pediatrics 2006;118:e594-e601.e601 [PubMed: 16950951]This study is important because it demonstrates that pediatricians should be concerned about elementary school children on the upper end of the BMI curves rather than reassuring parents that concerning weight trajectories will resolve over time. 
19. Eisenmann JC, Heelan KA, Welk GJ. Assessing body composition among 3- to 8-year-old children: anthropometry, BIA, and DXA. Obes Res 2004;12:1633-1640. [PubMed: 15536227]

20. Rolland-Cachera MF, Deheeger M, Maillot M, et al. Early adiposity rebound: causes and consequences for obesity in children and adults. Int J Obes (Lond) 2006;30(Suppl 4):S11S17.S17This article is important as it teaches us to be concerned with early adiposity rebound because it is associated with increased risk of both overweight and metabolic diseases.

21. Kolagotla L, Adams W. Ambulatory management of childhood obesity. Obes Res 2004;12:275-283. [PubMed: 14981220]

22. Reifsnider E, Flores-Vela AR, Beckman-Mendez D, et al. Perceptions of children's body sizes among mothers living on the Texas-Mexico border (La Frontera). Public Health Nurs 2006;23:488-495.495 [PubMed: 17096773] Mothers in this small convenience sample living on the Texas-Mexico border were unable to see their own children or pictures of overweight children as either overweight or unhealthy.

23. Eckstein KC, Mikhail LM, Ariza AJ, et al. Parents' perceptions of their child's weight and health. Pediatrics 2006;117:681-690.690 [PubMed: 16510647]This article is nice confirmation of parental misperception of overweight and the fact that parents are more likely to be concerned about older, overweight children, about children who suffered limitations related to weight or if they recalled a doctor's concern.

24. Jeffery AN, Voss LD, Metcalf BS, et al. Parents' awareness of overweight in themselves and their children: cross sectional study within a cohort (EarlyBird 21). BMJ 2005;330:23-24. [PubMed: 15567804]

25. Flower KB, Perrin EM, Viadro CI, et al. Using body mass index to identify overweight children: barriers and facilitators in primary care. Ambul Pediatr 2007;7:38-44.44 [PubMed: 17261481]This qualitative study of pediatricians reveals their frustrations regarding use of BMI in practice, but also highlights how BMI can be communicated to parents to motivate change. This study suggests the importance of incorporating the use of BMI into office systems and electronic records to foster routine use.

26. Perrin EM, Flower KB, Garrett J, et al. Preventing and treating obesity: pediatricians' self-efficacy, barriers, resources, and advocacy. Ambul Pediatr 2005;5:150-156. [PubMed: 15913408]

27. Chien A, Coker T, Choi L, et al. What do pediatric primary care providers think are important research questions? A perspective from PROS providers. Ambul Pediatr 2006;6:352-355.355 [PubMed: 17116610]Based on a large survey of Pediatric Research in Office Settings, providers believed that primary care research has inadequately addressed several lines of important inquiry including strategies to prevent and treat obesity (as well as the related effective counseling techniques and well child care effectiveness).

28. Spurrier NJ, Magarey A, Wong C. Recognition and management of childhood overweight and obesity by clinicians. J Paediatr Child Health 2006;42:411-418.418 [PubMed: 16898877]This new research confirms older research that general practitioners and pediatricians perform poorly when asked to determine weight status by visualization alone, and we believe would benefit from performing regular BMI screening.

29. O'Brien SH, Holubkov R, Reis EC. Identification, evaluation, and management of obesity in an academic primary care center. Pediatrics 2004;114:e154-e159. [PubMed: 15286251]

30. Perrin EM, Flower KB, Ammerman AS. Body mass index charts: useful yet underused. J Pediatr 2004;144:455-460. [PubMed: 15069392]

31. American Academy of Pediatrics. AAP publications retired or reaffirmed, October 2006. Pediatrics 2007; 119:405.This is an important reaffirmation of the 2003 American Academy of Pediatrics policy statement calling for the regular BMI screening of children to detect concerning weight trajectories as well as the encouragement of healthy dietary and activity behaviors.

32. Whitaker RC. Obesity prevention in pediatric primary care: four behaviors to target. Arch Pediatr Adolesc Med 2003;157:725-727. [PubMed: 12912775]

33. Perrin EM, Flower KB, Jacobson J, et al. The effect of a pediatrician 'toolkit' on children's nutrition and activity behavior change. Obesity 2006;14(Suppl):A247-A248.

34. Gonzalez JL, Gilmer L. Obesity prevention in pediatrics: a pilot pediatric resident curriculum intervention on nutrition and obesity education and counseling. J Natl Med Assoc 2006;98:14831488. [PubMed: 17019916] 
35. Goff SL, Holmboe ES, Curry L. Barriers to obesity training for pediatric residents: a qualitative exploration of residency director perspectives. Teach Learn Med 2006;18:348-355.355 [PubMed: 17144842]Based on in-depth interviews with residency program directors, this paper is helpful in defining some of the barriers to adding overweight and obesity training to the resident curriculum.

36. Perrin EM, Vann JJ, Flower KB, et al. Bolstering self-efficacy for nutrition and physical activity counseling in a pediatric resident clinic. Obesity 2006;14(Suppl):A247.

37. Kuczmarski RJ, Ogden CL, Guo SS, et al. 2000 CDC growth charts for the United States: methods and development. Vital Health Stat 2002;11:1-190.

38. Steinberger J, Jacobs DR, Raatz S, et al. Comparison of body fatness measurements by BMI and skinfolds vs. dual energy X-ray absorptiometry and their relation to cardiovascular risk factors in adolescents. Int J Obes (Lond) 2005;29:1346-1352. [PubMed: 16044176]

39. American Academy of Pediatrics. Policy statement: prevention of pediatric overweight and obesity. Pediatrics 2003;112:424-430. [PubMed: 12897303]

40. Dilley KJ, Martin LA, Sullivan C, et al. Identification of overweight status is associated with higher rates of screening for co-morbidities of overweight in pediatric primary care practice. Pediatrics 2007;119:e148-e155.e155 [PubMed: 17200242]This notable study examines the association between evaluation of and referral for comorbidities and low rates of accurate identification of atrisk-for-overweight or overweight children.

41. Institute of Medicine Committee on Prevention of Obesity in Children and Youth. Preventing childhood obesity: health in the balance. National Academies Press; Washington: 2004.

42. Woolford, SJ.; Clark, SJ.; Gebremariam, A., et al. A colorful plot: ways to increase physicians' use of BMI charts for preschoolers. Poster presentation at the 17th Annual Pediatric Research Symposium; Ann Arbor. 2006;

43. Rhee KE, De Lago CW, Arscott-Mills T, et al. Factors associated with parental readiness to make changes for overweight children. Pediatrics 2005;116:e94-e101. [PubMed: 15995022]

44. Gable S, Chang Y, Krull JL. Television watching and frequency of family meals are predictive of overweight onset and persistence in a national sample of school-aged children. J Am Diet Assoc 2007;107:53-61.61 [PubMed: 17197271] This longitudinal cohort study provides evidence to support a relationship between television viewing, family meal time and perception of outdoor activity safety and the onset of overweight in school-age children.

45. Davison KK, Marshall SJ, Birch LL. Cross-sectional and longitudinal associations between TV viewing and girls' body mass index, overweight status, and percentage of body fat. J Pediatr 2006;149:32-37.37 [PubMed: 16860123]This paper describes a longitudinal analysis of television viewing time for girls ages 7, 9 and 11, and offers some evidence of a positive relationship between overweight and television time exceeding the American Academy of Pediatrics recommendations.

46. Adachi-Mejia AM, Longacre MR, Gibson JJ, et al. Children with a TV in their bedroom at higher risk for being overweight. Int J Obes (Lond). 2006 [Epub ahead of print].This paper describes a crosssectional study providing evidence of a relationship between overweight and the location of a television in the child's bedroom, independent of physical activity level and participation in sports.

47. He M, Irwin JD, Bouck LM Sangster, et al. Screen-viewing behaviors among preschoolers parents' perceptions. Am J Prev Med 2005;29:120-125. [PubMed: 16005808]

48. Robinson TN. Reducing children's television viewing to prevent obesity: a randomized controlled trial. JAMA 1999;282:1561-1567. [PubMed: 10546696]

49. Ebbeling CB, Feldman HA, Osganian SK, et al. Effects of decreasing sugar-sweetened beverage consumption on body weight in adolescents: a randomized, controlled pilot study. Pediatrics 2006;117:673-680.680 [PubMed: 16510646]This describes an intervention study demonstrating the positive effects of reducing sugar-sweetened beverage consumption in particularly overweight adolescents.

50. O'Connor TM, Yang SJ, Nicklas TA. Beverage intake among preschool children and its effect on weight status. Pediatrics 2006;118:e1010-e1018. [PubMed: 17015497]

51. Sanchez A, Norman GJ, Sallis JF, et al. Patterns and correlates of physical activity and nutrition behaviors in adolescents. Am J Prev Med 2007;32:124-130.130 [PubMed: 17197153]This paper describes the results of a cross-sectional study examining the prevalence of certain adolescent health behaviors, including physical activity levels, television time, and fruit and vegetable consumption. 
52. Demattia L, Lemont L, Meurer L. Do interventions to limit sedentary behaviours change behaviour and reduce childhood obesity? A critical review of the literature. Obes Rev 2007;8:69-81.81

[PubMed: 17212797]This critical review is important because six of the 12 studies meeting inclusion criteria were clinic populations, and all approaches reduced sedentary behaviors and had benefits on weight control.

53. Floriani V, Kennedy C. Promotion of physical activity in primary care for obesity treatment/ prevention in children. Curr Opin Pediatr 2007;19:99-103.103 [PubMed: 17224670]This previously published review in Current Opinion in Pediatrics reviews the current literature on promoting physical activity as an important obesity treatment and prevention strategy.

54. Resnicow K, Davis R, Rollnick S. Motivational interviewing for pediatric obesity: Conceptual issues and evidence review. J Am Diet Assoc 2006;106:2024-2033.2033 [PubMed: 17126634]This is a well-written and honest review of the concept and evidence behind motivational interviewing. It describes the technique well and discusses its promise for this field as well as where the current evidence falls short.

55. Kant AK, Miner P. Physician advice about being overweight: association with self-reported weight loss, dietary, and physical activity behaviors of US adolescents in the National Health and Nutrition Examination Survey, 1999-2002. Pediatrics 2007;119:e142-e147.e147 [PubMed: 17200241]This is a fascinating secondary data analysis study that suggests: (1) half of overweight adolescents and more than $80 \%$ of at-risk adolescents do not report physicians ever telling them about their weight status, and (2) adolescents who have been told by their doctor about being overweight are more likely to have attempted weight control through moderate dietary behavior. 


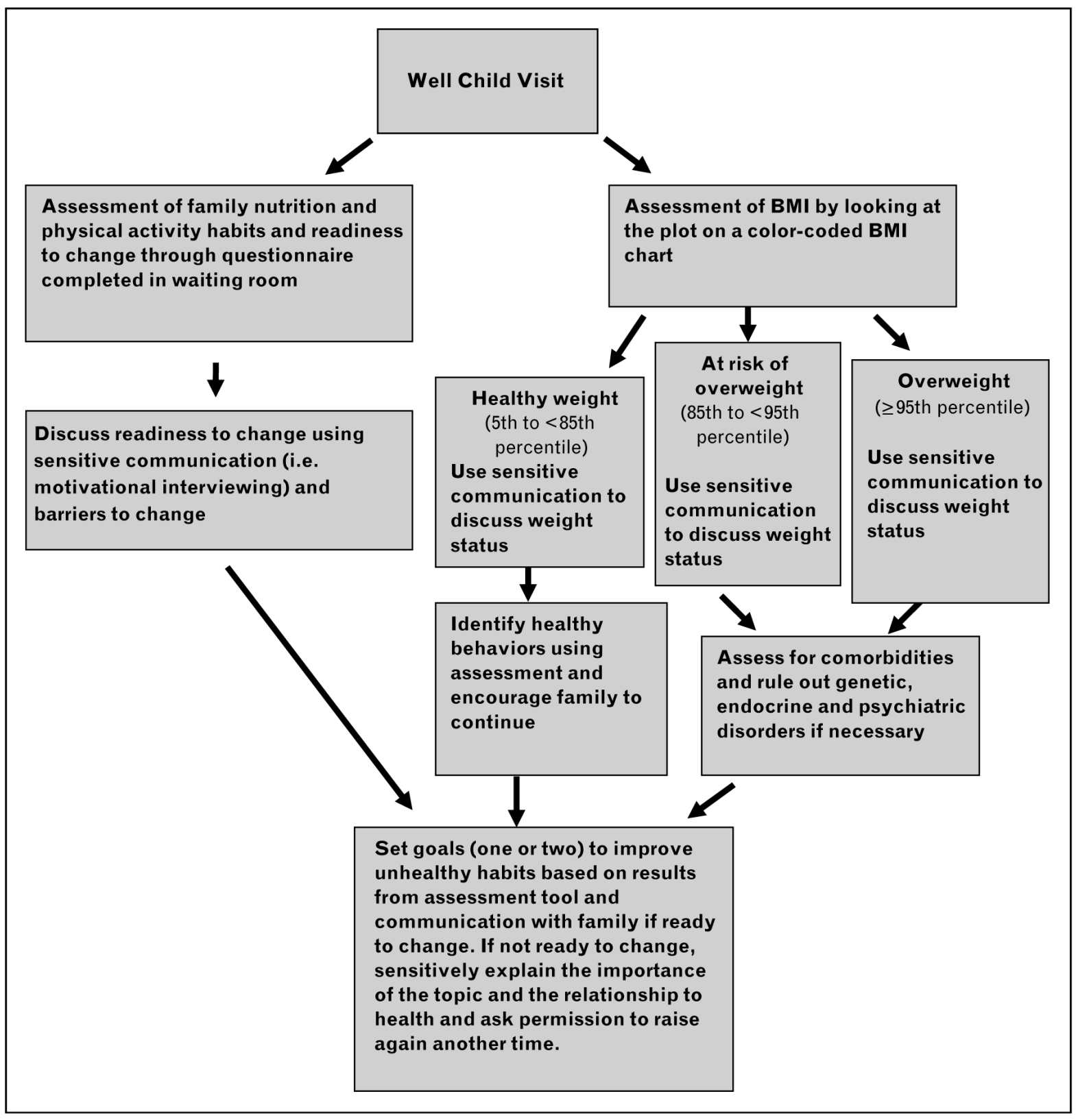

Figure 1. Plan for each well child visit

The plan incorporates assessment of dietary and physical activity habits and readiness to change, body mass index (BMI) weight status screening, and counselling. 
Table 1

Body mass index (BMI) categories and percentiles

\begin{tabular}{ll}
\hline BMI category & Percentile range \\
\hline Underweight & $<5$ th percentile \\
Healthy weight & 5 th to $<85$ th percentile \\
At risk of overweight & 85 th to $<95$ th percentile \\
Overweight & $\geq 95$ th percentile \\
\hline
\end{tabular}

Adapted from the Centers for Disease Control and Prevention, BMI — body mass index: about BMI for children and teens

(http://www.cdc.gov/nccdphp/dnpa/bmi/childrens_BMI/about_childrens_BMI.htm). 


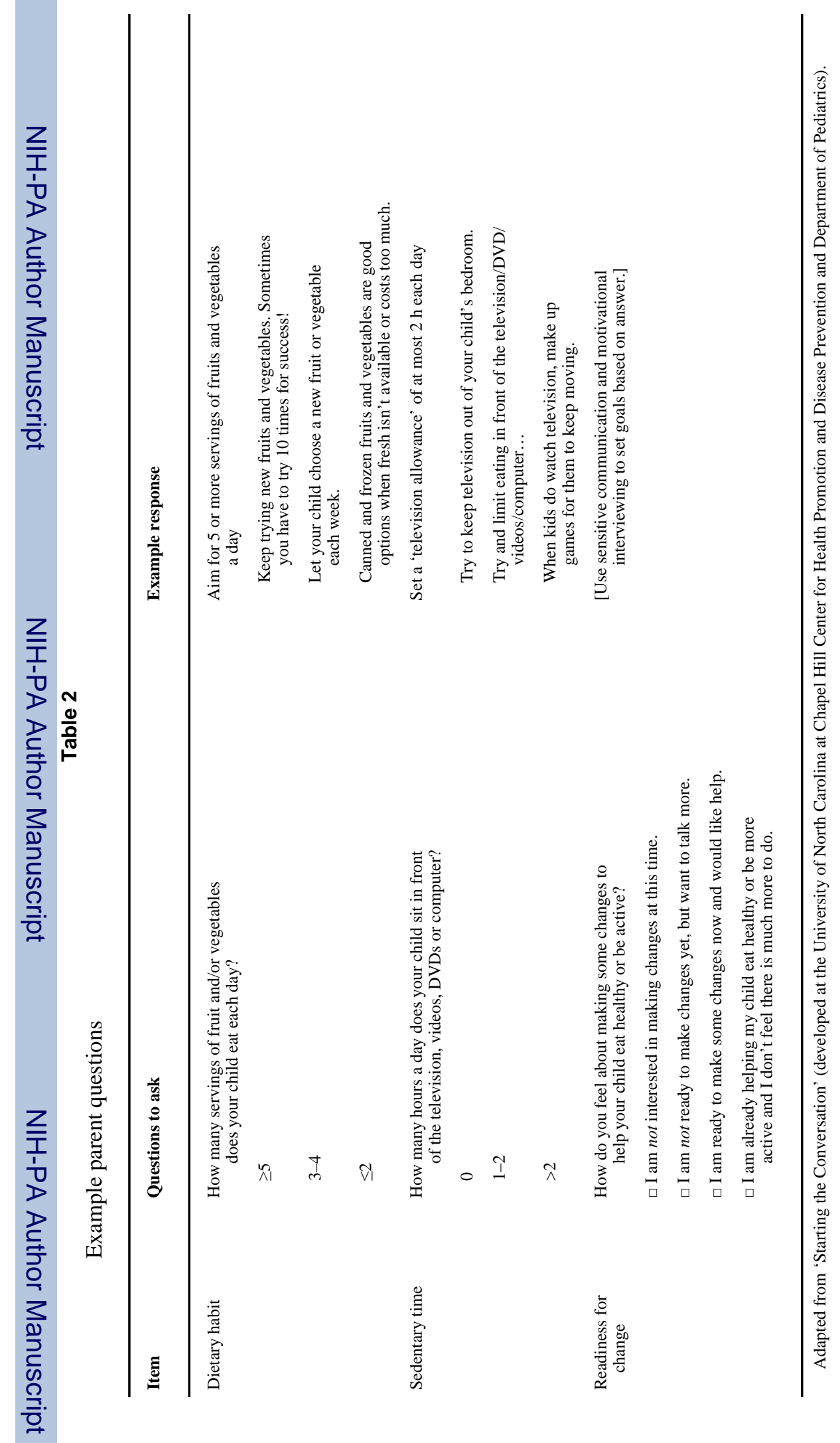




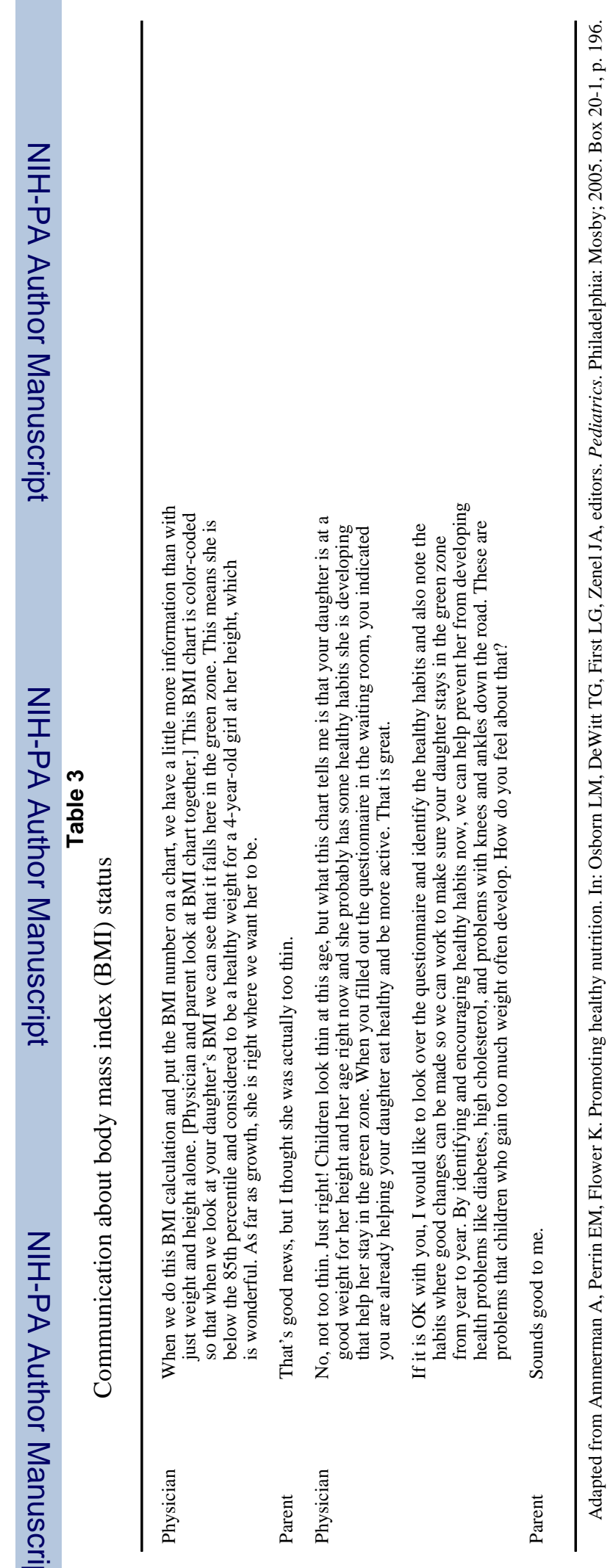

